JANE MEAD

\title{
Experience as Visitation
}

That which comes unwilled comes shiningPulls up the sun from out dark waters-

Moves through mist, a mind in motion-

(There is a harbor there, within you).

(Comes unwilled, comes shining) -

Wolves lift their heads to ghost-sound-

The bird inside the box, calling-

(Rose, birdcall, wind-come shining).

Comes of nothing comes, unbidden-

The lunar and the mutual mission-

The mutual order and the lack-

(Every ruptured and unclaimed fact).

That which comes unbidden comes directly-

(Comes unleashed, uncharted and-comes shining). 